\title{
EDITORIAL
}

\section{FILOSOFIA FRANCESA CONTEMPORÂNEA, UM LUGAR PARA O PENSAMENTO}

O trabalho de organização deste quarto número da Revista Limiar tem em vista a compreensão de que apreender verdadeiramente um pensamento ou uma teoria pressupõe o entendimento de que estes, ao se constituírem, pertencem não a um mundo abstrato, isolado, cindido e exterior àquele que comumente chamamos de real e concreto, mas que, ao contrário, por serem dados pela mediação precisa de um homem ou uma mulher que necessariamente vive, sofre e age no mundo, esse pensamento e essa teoria têm movimento, são igualmente vivos: tendo sido moldados pelo mundo sob uma mediação precisa, a do pensador ou da pensadora, são a expressão singular de um esforço humano para apreender, isto é, constituir, transformar, inventar em alguma medida esse mundo no qual todos vivemos e sobre o qual todos agimos. Perceber e entender como essas diferentes instâncias, a do pensamento e a da ação, se articulam, talvez venha a ser o que de mais interessante e precioso uma investigação histórica da filosofia pode oferecer.

Uma história da filosofia nesses moldes deve ultrapassar, por isso também, o movimento de uma simples contextualização, a partir do qual se busca encaixar numa história um pensamento em princípio exterior a ela, ou a vida deste e daquele autor numa dimensão em princípio paralela a do seu discurso, dos conceitos que ele mobiliza. Uma produção histórica da filosofia nos moldes aqui pressupostos ultrapassa, assim, a pretensão de circunscrever simplesmente um pensamento ou pensador em certo tempo e em certo lugar, num espírito de época, ou em circunstâncias materiais entendidas como determinantes para o seu surgimento, visando tão somente a busca de possíveis elos, elementos com os quais se torne possível o estabelecimento de relações de tipo causal: entendemos, pois, que um pensamento verdadeiramente vivo não se reduz a ser simplesmente causado pelo que quer que seja, mas constitui-se junto com a realidade, já que é parte dela.

Essa preocupação de ordem ético-metodológica e postura de ordem teórico-política nos parecem decisivas e significativas, uma vez que, a partir delas, o problema filosófico, ao se apresentar, virá a ser iluminado também pela concretude histórica à qual está visceralmente ligado, ou na qual ele está organicamente imbricado; mas será ainda, em contrapartida, a própria questão histórica e, no caso que aqui nos interessa em particular, a da filosofia considerada ou intitulada francesa contemporânea que se recolocará em termos, pode-se dizer, mais precisos.

Apresentamos a seguir certas leituras e posições de questões e problemas filosóficos que têm por certo a potência de por à luz movimentos próprios da história da filosofia, em especial na França do século XX, que a caracterizam e a revelam ao mesmo tempo. 
O campo metodológico em meio ao qual tais problemas então se presentificam, a saber, esse em que se cruzam filosofia e história, ou, mais precisamente, pensamento e ação, tem a vantagem suplementar, assim entendemos, de poder ao mesmo tempo recolocar a própria questão da possibilidade de uma filosofia dita francesa e contemporânea. Pois o faz também recusando de antemão a recaída em quadros restritivos nos quais vigoram certos pressupostos que, por seu turno, acabaram tornando inviável essa discussão, em particular para filósofos, na França e fora dela, ao longo do século XX. Dentre esses pressupostos presentemente recusados podemos destacar três dos mais esterilizantes, a nosso ver: o da existência de um suposto caráter nacional, suposto caráter de um povo ou nação ${ }^{1}$ que se refletiria também na produção filosófica de seus indivíduos; o de que produção e produto filosófico se estabelecem a partir de relações de causa e efeito, e que, portanto, toda a produção filosófica tem uma explicação causal para ser esta ou aquela e não aquela outra; o da existência, por fim, de características estilísticas (não exclusivamente discursivas, necessariamente, mas que podem ser também temáticas, ou mesmo metodológicas), como, por exemplo, a de uma suposta personalidade filosófica, que formataria por sua vez a expressão do indivíduo que filosofa.

Em suma, se acreditamos hoje poder falar de filosofia francesa contemporânea e mesmo reunir artigos sob essa rubrica - como, de fato, aqui o fazemos -, é porque entendemos que o que está em jogo, afinal, é muito mais a busca da constituição de um caminho em meio a um campo aberto e sem fronteiras do pensamento do que a chancela e, consequentemente, a reprodução direta ou disfarçada de ideias e teorias supostamente caracterizadas e oficialmente nomeadas.

O movimento de agrupamento dos escritos do dossiê que aqui apresentamos procura seguir certa sinuosidade cronológica, ou temporalidade não linear. Estabelece seu ponto de partida em questões e problemas ligados ao pensamento de autores mais recentes em relação ao momento presente. Assim sendo, a coletânea é aberta pelo ensaio de Pierre Montebello dedicado ao sentido da música de Pierre Boulez para Gilles Deleuze e ao possível alcance da arte deste compositor em relação à própria filosofia deleuziana. Com Montebello veremos, pois, que a música de Boulez estrutura certa sintonia tempo-espacial em que o tempo passado, reminiscência e também potência em vias de se atualizar, compõe com uma espacialidade - dada menos na categoria representacional da música do que na sua estrutura autônoma - que "atravessa os corpos" e os "desenraiza"; sintonia que remete ao tempo sensível que é igualmente devir e lastro no vivido, mas também a um espaço perceptivo não restrito e não restritivo; um lugar como pura estrutura, sem centro, sem auto-centramento, um nomadismo, no sentido propriamente deleuziano, mas então de um pensamento também musical. $\mathrm{O}$ artigo de Filipe Ferreira segue também pelas

1 Cujo verdadeiro patriota, no mais, tem o dever de defender e preservar, sobretudo em situações de conflito e de guerra, como foi o caso também da França do século XX. 
trilhas do pensamento de Deleuze, num sentido diverso desta primeira, contudo, igualmente original. A bem dizer, é precisamente a questão de uma origem que sua exposição apresenta e revela. Diz respeito, pois, a uma "nova concepção de imanência" e, com ela, de inconsciente surgida na obra deleuziana, em princípio com a reflexão que emerge do confronto efetivo entre sua "lógica dos sentidos" e toda a carga de não sentido encravada na relação do indivíduo esquizofrênico com seu próprio corpo. Do impacto produzido por esse confronto resulta, segundo Felipe Ferreira, o fundamento do projeto crítico e clínico de Gilles Deleuze em parceria com Félix Guattari.

Movendo-nos ainda em meio a esse primeiro momento do presente dossiê, encontraremos o artigo de Philippe Oliveira de Almeida dedicado à reflexão sobre a categoria de a priori histórico na filosofia de Michel Foucault. Num instigante percurso constituído por conceitos de Nietzsche, Heidegger e Wittgenstein, o autor alicerçará os fundamentos de sua abordagem acerca das "condições históricas de possibilidade", ou devir histórico, em Foucault, "abertura" ou épistheme em virtude da qual a história propriamente se faz como "acontecimento". Ainda segundo P. de Almeida, e como veremos, o "acontecimento" se efetiva como conjunto de regras de jogos de linguagem, isto é, como limites instituídos pelas práticas humanas, dentre as quais se encontra o próprio conhecimento humano.

O segundo movimento deste nosso volume leva ao ensaio de Marcos Camolezi dedicado ao tema da causalidade a partir da filosofia de Henri Bergson. Num trabalho finamente tecido por leituras e análises agudas que fazem repercutir a filosofia bergsoniana para além de seu momento próprio, Camolezi estrutura um enredo conceitual bastante preciso e rigoroso, em relação ao qual a causalidade torna-se núcleo de um projeto de amplo alcance por meio do qual as obras sobre a filosofia bergsoniana de Bento Prado Junior e de Franklin Leopoldo e Silva são não apenas explicitadas na originalidade e na magnitude que lhes são próprias, mas ainda tornadas afinadamente comunicantes entre si. Tendo o criticismo kantiano como ponto de referência constante nesse trânsito feito entre Bergson, Bento Prado Júnior e Franklin Leopoldo e Silva, teremos a oportunidade de reconstituir, junto com o autor, uma breve, contudo consistente história do bergsonismo no Brasil. Por meio desse estudo veremos compor-se não apenas tramas conceituais internas a um campo conceitual e teórico específico, mas, além disso, o elo histórico concreto entre elas, o qual, no mais, não se efetiva simplesmente como transição pacífica ou continuidade teórica homogênea de uma filosofia para outra, nem também, por outro lado, como oposição simétrica e sistemática de umas em relação às outras, mas antes como movimento próprio de (re)posição, de (re)colocação, ou mais precisamente - e para empregar o termo propriamente bergsoniano - de reinvenção de um problema filosófico preciso.

A última parte de nosso dossiê remete aos artigos dedicados à fenomenologia francesa, em particular, a dois de seus principais expoentes, Jean-Paul Sartre e Maurice Merleau-Ponty. O ensaio de Simeão Sass discorre sobre a noção de projeto existencial e a 
centralidade desta na obra de Sartre. Sendo uma espécie de fundo ou de estrutura fundamental que, como tal, liga internamente as obras e alguns dos seus temas mais caros - como, por exemplo, os de liberdade, de situação, de responsabilidade, entre outros - a noção de projeto será tomada principalmente na discussão que Sartre estabelece em Questões de método. Não se restringindo, contudo, a esta obra, S. Sass vai além. Partindo das indagações fundamentais surgidas com este que é um dos últimos escritos sartreanos, delineará com muita propriedade e desenvoltura o percurso retroativo pelos demais anteriores: de $O$ ser e o nada transitará por $O$ existencialismo é um humanismo a fim de alcançar, pois, o ponto alto de sua exposição, a saber, a reflexão fundamental, algo como motor da obra sartreana, sobre a realidade humana - realidade do desejo de ser, como ressalta S. Sass -, então submetida ao novo crivo epistemológico, como poderemos ver, da psicanálise existencial.

$\mathrm{O}$ segundo artigo voltado à filosofia sartreana, escrito em conjunto por Gustavo $\mathrm{Fu}-$ jiwara e Beatriz Zanfra, não deixa de se ligar em certo sentido compositivo com o primeiro. Dedicado ao tema da moral então compatível com o projeto fenomenológico centrado principalmente nas primeiras obras A Transcendência do Ego e Esboço de uma teoria das emoções, nele será deslindada a noção de $E u$, em Sartre, cuja análise aprofunda, como veremos, certo percurso científico, que parte da abstração do cogito e do ego transcendental em direção à concretude do $E u$. A discussão a respeito deste último emergirá, por sua vez, segundo G. Fujiwara e B. Zanfra, da recolocação ou refundação da questão fundamental da intencionalidade, sobre a qual serão alicerçadas, pois, as novas e originais filosofia da consciência e teoria das emoções sartreanas.

No terceiro artigo desse último bloco do dossiê de filosofia francesa contemporânea, Wanderley J. Ferreira Júnior abordará o tema da linguagem e da expressão a partir da ontologia selvagem de Merleau-Ponty, na qual se propõe a adentrar. Privilegiando a abordagem temática de $O$ visível e o invisível, Wanderely Ferreira Jr. discorrerá sobre a questão do alcance, ou da (im)potência da linguagem e da expressão - que, por natureza, nunca poderão esgotar o sentido do significado a ser exprimido -, a partir da retomada da relação entre consciência perceptiva e consciência representativa. Do resultado dessa reflexão, o autor apontará para o que chamará de "algumas perspectivas abertas pela ontologia selvagem proposta por Merleau-Ponty para tornar dizível e exprimível essa experiência muda e não objetificante do mundo e de nosso próprio corpo".

O presente volume da Limiar se encerra com as traduções de dois ensaios de Gilles Deleuze, introduzidas por Sandro Fornazari e realizadas por ele e por Juliana Oliva. Da perspectiva cronológica, esses dois textos de Deleuze se encontram, pode-se dizer, em dois extremos opostos de trajetória filosófica. O primeiro, Descrição da mulher. Por uma filosofia de outrem sexuada, diz respeito ao escrito de um Deleuze jovem, no início de seu percurso; o segundo, Imanência: uma vida, ao seu último. Como destaca S. Fornazari 
na apresentação das traduções, se, no primeiro texto - cuja tradução oferece rigor e zelo em relação ao espírito original -, Deleuze procura dar destaque à questão da identidade desse eu concreto do ser mulher, isto se deve em boa medida ao propósito de justamente por em questão um elemento importante dessa concretude. Ainda que não abstrato como se julgava ser o da metafísica e da psicologia então rechaçadas pelos fenomenólogos, esse eu falha em alguma medida em sua concretude: trata-se de um eu assexuado - o que exclui dele, fundamentalmente, o sexo feminino, o qual torna-se o outro, dada a histórica associação, no campo reflexivo inclusive, do sujeito ou da individualidade "neutra" ao sexo masculino. Em Imanência: uma vida, a linha mestra será traçada pela resposta à pergunta sobre o que seja um campo transcendental e sobre qual a relação deste com a consciência. Na medida em que esse é o campo no qual o real se faz anterior à realidade empírica e, com ela, à cisão entre sujeito e objeto, a relação do campo transcendental com a consciência, como mostrará Deleuze, só poderá ser uma relação de direito e não de fato. As implicações dessa discussão, posta nesses termos iniciais, é o que essa tradução apurada e cuidadosa de S. Fornazari irá nos oferecer.

Assim procuramos seguir os caminhos abertos por expressões diversas da filosofia francesa ao longo do século XX, pelas tramas, questões e pelos problemas que estas têm a oferecer, e, ainda, por tudo a que elas nos conduzem também aqui, em nosso tempo e lugar, em meio ao nosso campo de ação e de criação possíveis (e de possíveis). Apenas levando preliminarmente esse todo em conta é que ousamos dizer, por fim, que o que está em jogo aqui é, pois, história de certa filosofia francesa contemporânea. Apoiando-nos na célebre sentença merelaupontyana sobre a relação entre objetividade e subjetividade na história da filosofia, dizemos que teremos, pois, algo relacionado a uma retomada subjetiva (de um problema, de um conhecimento), narração e reflexão, mas não reflexão livre $^{2}$. Ou ainda, nas nossas próprias palavras, um modo de ser reflexão que não poderá ser nem exclusivamente nativa, nem também marginalmente estrangeira (ou de estrangeiros), mas, antes, um gesto ou ação do pensamento constituído também na e pela expressão de pesquisadores e estudiosos cuja história própria e diversa integra e integrará - como, no mais, não poderia deixar de ser - esse tempo histórico e conceitual propriamente vivo e essencial para o que aqui se acredita poder nomear-se filosofar.

Izilda Johanson

dezembro de 2015

\footnotetext{
2 "Toute I'histoire de la philosophie est une reprise personnelle par le philosophe du problème qui'il etudie; reprise subjective, donc doctrine et philosophie, narration et réflexion - mais non pas réflexion libre. [...] L'objectivité de l'histoire de la philosophie ne se trouve que dans l'exercice de la subjectivité. Le moyen de comprendre un système c'est de lui posé les questions dont nous nous soucions nos-mêmes: c'est ainsi que les systèmes apparaissent avec leurs differences, qu'ils attestent si nos questions sont identique à celles que se posaient leurs auteurs" (L'union de l'ame et du corps chez Malebranche, Biran et Bergson, Paris, Vrin, 2002, p. 11).
} 